http://doi.org/10.15359/ree.12-1.10

\title{
LA TEORÍA DE LAS INTELIGENCIAS MÚLTIPLES EN LA PRÁCTICA DOCENTE EN EDUCACIÓN PREESCOLAR
}

\author{
Karina Lizano Paniagua ${ }^{1}$ \\ Estudiante de la maestría en Psicopedagogía de la Universidad Estatal a Distancia \\ San José, Costa Rica \\ Mónica Umaña Vega ${ }^{2}$ \\ Estudiante de la maestría en Psicopedagogía de la Universidad Estatal a Distancia \\ San José, Costa Rica
}

Recibido 18 de noviembre 2005 • Aprobado 21 de setiembre 2006

\begin{abstract}
Resumen: Este artículo presenta los resultados obtenidos de la aplicación de una propuesta curricular basada en la Teoría de las inteligencias múltiples en la práctica educativa en Educación Preescolar; y surgió como producto del trabajo de investigación realizado para optar por el grado de Licenciatura.
\end{abstract}

Palabras clave: Inteligencias Múltiples, Educación Preescolar, Propuesta Curricular, Práctica Educativa.

\begin{abstract}
This article presents the results of the application of curricular proposal based on the Multiple Intelligences Theory on Educational practice in Preeschool Education
\end{abstract}

Key words: Multiple Intelligences, Preeschool Education.

\section{INTRODUCCIÓN}

La Teoría de las inteligencias múltiples plantea la existencia de ocho formas para aprender, unas más desarrolladas que otras, según las personas. De este modo, los individuos son capaces de conocer el mundo por medio del lenguaje, del análisis lógico-matemático, de la representación espacial, el pensamiento musical, el uso del cuerpo para resolver problemas o hacer cosas, de una comprensión de los demás individuos y de nosotros, así como del contacto con el medio que los rodea.

Campbell, Campbell y Dickenson (2000) aseguran que las inteligencias múltiples son “...lenguajes que hablan todas las personas y se encuentran influenciadas, en parte por la cultura a la que cada una pertenece. Constituyen herramientas que todos los seres humanos pueden utilizar para aprender para resolver problemas y para crear" (p. 12).

Estudiante de la maestría en Psicopedagogía de la Universidad Estatal a Distancia. Licenciada en Pedagogía con énfasis en Educación Preescolar de la Universidad Nacional.

2 Estudiante de la maestría en Psicopedagogía de la Universidad Estatal a Distancia. Licenciada en Pedagogía con énfasis en Educación Preescolar de la Universidad Nacional. 


\section{TIPOS DE INTELIGENCIAS}

\section{Inteligencia lingüística}

Para Campbell (2000) la inteligencia denominada lingüística “...consiste en la capacidad de pensar en palabras y de utilizar el lenguaje para expresar y apreciar significados complejos” (p. 12). Es decir, se refiere a la habilidad para utilizar las palabras efectivamente.

Gardner (citado por Mora y Vindas, 2002) agrega que una habilidad de las niñas y niños con mayor desarrollo en esta inteligencia, es la sensibilidad hacia los sonidos, ritmo y significado de las palabras, así como hacia las diferentes funciones del lenguaje.

En lo que respecta a los usos fundamentales del lenguaje, Gardner (1983) establece cuatro: la retórica, la explicativa, la memorística y la metalingüística.

- $\quad$ La retórica: referida a la habilidad para convencer a los demás acerca de alguna situación; es decir, el poder de convencimiento.

- La explicativa: hace referencia a la capacidad para explicar conceptos e ideas.

- La memorística: permite almacenar información para recordarla después.

- La meta-linguística: es la capacidad para reflexionar a cerca del empleo del lenguaje.

Por su parte, Armstrong (citado por Mora y Vindas, 2002) asegura que a los individuos les gusta leer, escribir y contar historias; “...son buenos para memorizar nombres, lugares o fechas; aprenden mejor hablando, escuchando y mirando palabras; además, poseen sensibilidad hacia los sonidos, ritmo, significado de las palabras y para las diferentes funciones del lenguaje" (p. 7).

Dentro de la inteligencia lingüística existen, según Campbell et al. (2000), cuatro habilidades esenciales que se desarrollan en los individuos y que son importantes de potenciar en la niña y el niño para lograr un desempeño más óptimo, a saber: la escucha, el habla, la lectura y la escritura.

- La escucha: las personas necesitan escuchar para aprender a utilizar la palabra hablada en forma eficaz y elocuente, destacando que un mal dominio de dicha habilidad puede ocasionar fracasos escolares, malentendidos y lesiones físicas.

- $\quad$ El habla: esta se convierte en otra habilidad importante que, para desarrollarse, necesita de una fuerte dosis de práctica y estímulos que permitan avanzar, así como realizar oraciones más complejas y lógicas.

Campbell et al. (2000) mencionan que “...la expresión verbal es un ejercicio metacognitiva importante, ya que permite obtener unas percepción más profunda de lo que realmente pensamos y sabemos" (p. 23). La expresión verbal ayuda a reflexionar a cerca de las acciones, así como de los propios conocimientos que se posean con respecto a los aprendizajes construidos.

La lectura y la escritura constituyen procesos meta cognitivos importante, pues le permiten al individuo reflexionar acerca de las ideas que desea expresar y las que anota en el papel. Cabe destacar que para la escritura y lectura eficaz, se requiere de prácticas que permitan coordinar los pensamientos con las letras, así como realizar una lectura profunda de lo que se lee.

Mora y Vindas (2002) proponen un listado de materiales para esta inteligencia: libros (de cuentos, poesías, trabalenguas e historias), revistas y periódicos, tarjetas con letras, láminas de vocabulario, juegos de palabras y materiales para escribir. 


\section{Estrategias para estimular la inteligencia lingüística en las niñas y los niños}

Es fundamental estimular al niño o la niña desde temprana edad para que empiece a reconocer las palabras como una forma de comunicarse y expresar sentimientos, debido a que el lenguaje se constituye en una función esencial del ser humano, que le brinda posibilidades de explorar y expandir la inteligencia. Si bien es cierto, esta función es innata en el individuo, pues se nace con la predisposición para aprender el lenguaje, el papel que cumple la sociedad permite su desarrollo, el establecimiento de procesos de comunicación eficaz.

Verney (citado por Campbell et al, 2000), plantea “...la importancia de crear entornos lingüísticamente ricos en los que los padres o las personas que tengan niños a su cuidado promuevan interacciones verbales con los pequeños, incluyendo juegos de palabras narración de cuentos y chistes, formulación de preguntas, solicitud de opiniones, explicación de sentimientos y conceptos" (p. 22). El hecho de que el ambiente y las personas estimulen esta inteligencia, potencia su grado de aprendizaje y utilización eficaz, influyendo de manera positiva en el desenvolvimientointegral del niño facilitando las competencias lingüísticas que empleará durante toda su vida.

Por su parte, Walkman (citada por Gatgens, 2003) destaca la importancia de promover en la clase un ambiente rico en lenguaje, donde se estimulen los estudiantes mediante el uso constante del habla, la lectura, la escucha y el estudio de las palabras. Para ello, es indispensable brindar oportunidades donde el o la estudiante pueda debatir aspectos, relatar acontecimientos, realizar presentaciones orales y hacer preguntas, además de instarlos a interpretar fotografías, entrevistas y periódicos.

Asimismo, la o el docente debe planear visitas a librerías, bibliotecas y editoriales, en los cuales se incentive el interés de los niños hacia la lectura y el uso del lenguaje.

\section{Inteligencia lógico matemática}

Campbell et al. (2000) señalan que la inteligencia lógico-matemática "permite calcular, medir, evaluar proposiciones e hipótesis y efectuar operaciones mentales complejas"(p.12). Se basa en la capacidad para trabajar, de manera adecuada, con los números, establecer relaciones entre ellos, utilizar la lógica y el raciocinio.

Armstrong (2001) argumenta que "...los niños que son fuertes en este tipo de inteligencia piensan de forma numérica o en términos de patrones y secuencias lógicas, y utilizan otras formas de razonamiento lógico" (p. 29). Lo que permite resolver dificultades de diferentes maneras.

Esta inteligencia, según Walkman (citada por Gatgens, 2003), abarca tres campos amplios e interrelacionados: la matemática, las ciencias y la lógica. Estos aspectos se desarrollan cuando el niño y la niña se confrontan con los objetos físicos, y termina con el entendimiento de las ideas abstractas. A lo largo de este proceso, la persona desarrolla una capacidad de discernir patrones lógicos o numéricos y de trabajar largas cadenas de razonamiento (p. 18).

Campbell et al. (2000) consideran que la inteligencia lógico matemática incluye varios componentes: cálculos matemáticos, pensamiento lógico, solución de problemas, razonamiento deductivo (del todo a las partes) e inductivo (de las partes al todo) discernimiento de modelos y relaciones. Cabe destacar que este planteamiento reemplaza la concepción de la Matemática, que anteriormente enfocaba el desarrollo del cálculo y el álgebra, y que se incluyen la solución de problemas, el razonamiento y la elaboración de conexiones y comprobación de hipótesis, habilidades que más útiles 
que sumar o restar, ya que son aplicables a todos los campos de estudio; por eso la utilización del pensamiento abstracto es indispensable en esta inteligencia.

Armstrong (citado por Mora y Vindas, 2002) considera que los individuos con esta inteligencia más desarrollada, presentan algunas de las siguientes características: les gusta experimentar, trabajar con números, hacer preguntas y explorar patrones y relaciones; son buenos para la matemática, razonamiento, para la lógica y la resolución de problemas; aprenden mejor categorizando, clasificando, estableciendo patrones y relaciones, así como realizando trabajos abstractos; poseen la sensibilidad y capacidad para discernir, razonar o relacionar números, y habilidad para sostener largas cadenas de razonamiento y establecer relaciones de causa-efecto.

\section{Estrategias para estimular la inteligencia lógico-matemática en las niñas y niños}

Walkman (citada por Gatgens, 2003) plantea que para estimular esta inteligencia, es necesario que las niñas y los niños experimenten, clasifiquen y analicen los objetos presentes en el medio que les rodea. Es importante que los y las docentes promuevan el trabajo con los números, para que sus estudiantes noten su existencia y más adelante puedan comprenderlos.

Es importante promover actividades en las cuales las y los niños elaboren bosquejos, resuelvan analogías, o bien, encuentren relaciones.

\section{Inteligencia espacial}

Campbell et al. (2000) manifiesta que la inteligencia espacial “...proporciona la capacidad de pensar en tres dimensiones. Permite al individuo percibir imágenes externas e internas, recrearlas, transformarlas y modificarlas, recorrer el espacio o hacer que los objetos lo recorran y producir o decodificar información gráfica (p. 12). Estos autores relacionan esta inteligencia con la parte visual y plantean que se constituyó en la primera forma de expresión del ser humano, pues antes del surgimiento de la escritura y la matemática, las imágenes fueron utilizadas como códigos para representar las ideas.

La inteligencia visual-espacial, según Walkman (citada por Gatgens, 2003), “...empieza a surgir con la infancia y continúa desarrollándose durante toda la vida” (p. 21).

Esta misma autora propone que la inteligencia espacial “...se basa en los objetos, funciona con el mundo concreto de los objetos y sus ubicaciones; es la base de la vida humana” (p. 22).

Desde este punto de vista, conviene destacar la definición que plantea Armstrong (2000), al conceptualizarla como la inteligencia de las imágenes, debido a que comprende una serie de habilidades como discriminación visual, reconocimiento, proyección, imagen mental, razonamiento espacial manejo y reproducción de imágenes de exteriores e interiores.

Esta inteligencia no se enmarca estrictamente en el sentido de la vista, puesto que las personas, con alguna deficiencia visual, tienen amplias probabilidades de desarrollarla y manejarse en el espacio, de lo contrario, no se explicaría cómo hacen para movilizarse.

Armstrong (citado por Mora y Vindas, 2002) retoma algunas características que desarrollan las personas con esta inteligencia, como que les gusta dibujar, construir, diseñar, crear cosas, soñar, mirar pinturas, diapositivas, ver películas y jugar con máquinas. Son buenos para imaginar cosas, resolver rompecabezas, laberintos, leer mapas, gráficos, y además, percibir los cambios que suceden 
a su alrededor. Aprenden mejor visualizando, soñando, usando pensamiento abstracto y trabajando con colores y fotos. Poseen sensibilidad al color, línea, forma, figura, espacio y hacia la relación existente entre estos elementos.

Este autor considera que las personas con afinidades hacia esta inteligencia “...parecen saber dónde está ubicado todo... muchos desarrollan una gran fascinación por máquinas o aparatos extraños y en ocasiones inventan objetos" (Armstrong, 2001, p.3 1).

\section{Estrategias para Estimular la Inteligencia Espacial en los niños y en las niñas}

Walkman (citada por Gatgens, 2003) recomienda que, para estimular la inteligencia espacial, es necesario ofrecer un ambiente visualmente rico, con imágenes, fotografías y color; para potenciar su desarrollo se plantea la necesidad de utilizar mapas, cuadros, así como valerse de dibujos, construcción de modelos, resolución de rompecabezas y uso del color. Se sugiere realizar juegos de memoria visual, hacer ejercicios de imaginación guiada o simulada, así como aprovechar los vídeos, filminas, telescopios y diagramas.

Mora y Vindas (2002) proponen un listado de materiales para favorecer esta inteligencia: mapas, geoplanos, rompecabezas, legos, gráficos, diagramas, ilustraciones, cintas de vídeos, modelos tridimensionales, materiales para artes plásticas, piedras, materiales para moldear y crear.

\section{Inteligencia físico cinestésica}

Para Campbell et al. (2000), la inteligencia físico cenestésica, "le permite al individuo manipular los objetos y perfeccionar las habilidades físicas" (p. 12). Tiene que ver con la habilidad para utilizar el cuerpo como forma de expresión y comunicación.

Valverde (2003) postula que la inteligencia físico cinestésica es “...la habilidad para ejecutar movimientos manuales y corporales en forma controlada y especializada, para expresar ideas y sentimientos, así como para ejecutar hábilmente gestos y movimientos corporales” (p. 51).

Conviene recalcar que la inteligencia corporal cinestésica ocupa un lugar importante dentro de los desarrollos cognitivo, social y lingüístico del niño, pues éste aprende mediante la interacción de los sentidos, los objetos y las acciones, que sólo se logra a través del cuerpo y los movimientos que éste deba realizar para explorar e investigar el mundo.

Walkman (citada por Gatgens, 2003) afirma que la inteligencia cinestésica “...comienza con el control de los movimientos automáticos y voluntarios y se desarrolla mediante la utilización del cuerpo y de formas altamente diferenciadas" (p. 19). Esto quiere decir que la manipulación del cuerpo y la habilidad de trasformar una intención en una acción, son aspectos muy importantes de esta inteligencia.

El control de los movimientos del cuerpo se localiza en la corteza motora, y cada hemisferio cerebral domina o controla los movimientos corporales del lado opuesto.

Armstrong (2001) manifiesta que:

Estos niños son inquietos a la hora de comer, son los primeros que piden permiso para retirarse y salir corriendo a jugar al parque... algunos tienen el don del bailarín o del atleta, del actor o del mimo, son buenos para remedar cualidades y defectos. Otros 
pueden ser especialmente dotados en motricidad fina y ser excelentes mecanógrafos y dibujantes, hábiles para la costura, las manualidades y las reparaciones u otras actividades relacionadas (p. 33).

Si bien es cierto, en la sociedad occidental las habilidades físicas no cuentan con tanto reconocimiento como las cognitivas, (puesto que estas últimas son las que se trabajan con mayor ahínco en la escuela), la capacidad de utilizar el movimiento puede ser aprovechada en otros ámbitos de la vida, incluso su uso constituye una necesidad de supervivencia y en una condición importante para el desempeño de muchos roles.

Armstrong (citado por Mora y Vindas, 2002) menciona algunas características que desarrollan las personas con esta inteligencia, entre ellas, les gusta moverse, tocar, hablar, utilizar el lenguaje corporal; son buenos para actividades físicas como deportes, bailes, la actuación y el diseño; aprenden mejor tocando, moviéndose, interactuando en el espacio y procesando el conocimiento a través de las sensaciones corporales. Poseen habilidades físicas específicas como la coordinación, el equilibrio, la destreza, la fuerza, la flexibilidad y la velocidad, así como habilidades propioceptivas, táctiles, ópticas y para manipular objetos.

Las autoras citadas proponen un listado de materiales para estimular esta inteligencia: vestuario, máscaras, escenarios, títeres, telas, bloques, utensilios de cocina y jardinería, bolas, sacos, aros, cuerdas, elásticos, mecates, pinturas, arcilla, materiales para texturas, martillos, agujas, granos y botones.

\section{Estrategias para estimular la inteligencia físico cinestésica}

Walkman (citada por Gatgens, 2003) propone actividades que impliquen movimientos físicos, como: dramatizaciones, mímica, charadas, bailes y deportes. Asimismo, deben brindarse oportunidades para que los estudiantes manipulen y toquen objetos. Para ellos, el trabajo con la pintura, la arcilla y la construcción, es de vital importancia.

El o la docente ha de planear excursiones a parques, museos de arte, al ballet y visitar exposiciones de artesanías.

\section{Inteligencia musical}

La inteligencia musical está constituida por personas sensibles al ritmo, a la melodía, al tono y a la armonía. Se relaciona con las habilidades y afinidades que se tengan con respecto a la música y otras formas de expresión rítmica.

El hemisferio derecho del cerebro desempeña un papel importante en la percepción y producción musical.

Armstrong (2001) señala que las niñas y los niños “...se identifican de inmediato por su forma de moverse y cantar cuando están oyendo música... tienen opiniones claras a cerca de sus preferencias musicales... son sensibles a los sonidos no verbales en el ambiente como el canto de los grillos y el tañido de campanas, oyendo cosas que los demás pasaron por alto" (p. 35).

La música se constituye en un medio de expresión de sentimientos y emociones, las niñas y los niños son probablemente las personas que utilizan más la música como medio para descansar, 
jugar, disfrutar o realizar cualquier actividad de aprendizaje; es un acto espontáneo que los motiva a poner ritmo a lo que hacen.

Walkman (citada por Gatgens, 2003) recalca que la inteligencia musical ocasiona un gran impacto en el estado del cerebro humano, y que los primeros años de la niñez se consideran los más cruciales para el crecimiento del desarrollo musical.

Armstrong (citado por Mora y Vindas, 2002b) destaca las siguientes características en los individuos que poseen esta inteligencia: “...les gusta cantar, entonar, tocar instrumentos, escuchar y responder a la música; son buenos para memorizar canciones, recordar melodías, ritmos y mantener el tiempo en una pieza musical; aprenden mejor si se utilizan ritmos, melodías, canciones y música en general. Poseen sensibilidad al ritmo, compás y melodía y el timbre o tonalidad de una pieza musical, así como la comprensión figurada (global, intuitiva) o formal (analítica, técnica) de la música” (p. 11).

\section{Estrategias para estimular la inteligencia musical en las niñas y en los niños}

Las niñas y los niños disfrutan de la música y del movimiento, por lo que se les debe proporcionar un ambiente alegre que les permita exteriorizar todo la energía que tienen en su interior; para ello se les debe invitar a que reflexionen por medio de la audición acerca de los diferentes sonidos, ritmos y canciones que escucha.

Zamora (1999) plantea que la apreciación musical se da en tres etapas: "...la sensorial o intuitiva, en el momento de la audición; la intervención de la inteligencia, para dar sentido a la experiencia obtenida y por último, la apreciación crítica que se produce en el plano conciente por medio de la discriminación y la comparación" (p. 11).

Walkman (citada por Gatgens, 2003) menciona la importancia de promover actividades de canto, baile, escucha de grabaciones, así como la creación de instrumentos musicales, con el objetivo de que los estudiantes se expresen mediante la música. También recomienda que el docente utilice música de fondo, mientras los estudiantes trabajan. Se deben planear visitas a la sinfónica o a observar una obra musical.

Mora y Vindas (2002) recomiendan los siguientes materiales: grabadoras, cassettes, micrófonos, instrumentos musicales, botellas de sonidos, canciones de todo tipo, cintas de papel.

\section{Inteligencia interpersonal}

De acuerdo con Campbell et al. (2000), la inteligencia interpersonal es

La capacidad de comprender a los demás e interactuar eficazmente con ellos. A medida que la cultura occidental ha comenzado a reconocer la relación que existe entre la mente y el cuerpo, también ha comenzado a valorar la importancia de alcanzar la excelencia en el manejo de la conducta interpersonal (p. 13).

Por su parte, Armstrong (2001) añade que los niños dotados de esta inteligencia “...entienden a la gente... suelen ser excelentes mediadores de conflictos entre compañeros, dada su increíble capacidad de captar los sentimientos, las intenciones de los demás... aprenden mejor relacionándose y colaborando" (p. 37). Considera que a estos individuos les gusta hacer amigos, hablar con la gente e integrar grupos; son buenos para entender a los demás, liderar, organizar, son comunicativos y 
buenos mediadores en los conflictos; aprenden mejor compartiendo, relacionándose, cooperando y entrevistando. Poseen la capacidad de percibir y a la vez comprender la conducta, las emociones y motivaciones de las personas que le rodean. Además, son sensibles a las expresiones faciales, a la voz y a los gestos de los demás.

Para Walkman (citada por Gatgens, 2003), en las primeras etapas de esta inteligencia, las y los niños sólo pueden discernir y detectar los estados de ánimo de las personas que le rodean; sin embargo, conforme se desarrollan, logran leer las intenciones y deseos de las personas y actuar basados en ellos.

En este sentido, se deduce que estas personas son muy empáticas y fomentan relaciones buenas y estables con las demás personas. Se evidencia que son un gran apoyo para quienes atraviesan momentos difíciles en su vida, ya que tienen la capacidad de ayuda y cooperación innata, la cual va más allá de las dificultades.

Cabe destacar que quien tiene inteligencia interpersonal, posee la capacidad de discernir cuáles son sus amistades y por qué las conserva; pueden buscar amistades guiándose por el grado de seguridad que estas le brinden. Con base en esto, Antunes (2000) expresa que la inteligencia interpersonal "...se basa en al capacidad de percibir diferencias en los demás, particularmente contrastes en sus estados de ánimo, sus motivaciones, sus intenciones, y su temperamento” (p. 72).

\section{Estrategias para estimular la Inteligencia interpersonal en los niños y en las niñas}

Walkman (citada por Gatgens, 2003) recomienda que la clase ofrezca un ambiente de aceptación y apoyo donde las y los estudiantes puedan interactuar, escuchando activamente, brindando opiniones y expresando sus sentimientos.

Mora y Vindas (2002) apuestan por el uso de títeres, disfraces, fotografías, láminas, música, libros, películas, espejos, material para realizar un diario personal.

\section{Inteligencia intrapersonal}

Según Campbell et al. (2000), la inteligencia intrapersonal “...se refiere a la capacidad de una persona para construir una percepción precisa respecto de sí misma y utiliza dicho conocimiento para organizar y dirigir la propia vida (p. 13).

Dentro de las estrategias para estimular esta inteligencia, Walkman (citado por Gatgens, 2003) recomienda promover un ambiente que respete la autoestima de las personas, así como promover espacios donde el niño y la niña trabajen y aprendan independientemente. Además, se debe motivar el uso de actividades que promuevan el uso de la imaginación.

Por su parte, los docentes deben fomentar el trabajo en espacios silenciosos y lugares privados, donde el niño y la niña puedan trabajar y reflexionar. Deben ofrecer proyectos de largo plazo, para que las y los estudiantes puedan explorar sus intereses y habilidades; se les debe motivar para el uso del portafolio; se les ha de ofrecer actividades donde exploren sus valores, creencias y sentimientos. Mora y Vindas (2002) recomiendan fotografías, material para hacer un diario personal, libros y espejos.

\section{Inteligencia naturalista}

Campbell et al. (2000) manifiestan que “...consiste en observar los modelos de la naturaleza, en identificar, clasificar objetos y en comprender los sistemas naturales y aquellos creados por el 
hombre" (p. 13). Tiene que ver con la sensibilidad evocada a la protección y manejo responsable de los recursos naturales.

Para Lapalma (s.f.), "Es la capacidad de distinguir, clasificar y utilizar elemento del medioambiente, objetos, animales o plantas. Tanto del ambiente urbano como suburbano o rural, incluye las habilidades de observación, experimentación, reflexión y cuestionamiento de nuestro entorno” (p. 8).

Por su parte, Antunes (2000) dice que las personas con inclinaciones hacia esta inteligencia sienten una atracción profunda por el mundo natural, así como hacia todo lo que no ha sido creado por el ser humano.

En este sentido, es necesario rescatar que las y los niños con inclinaciones hacia esta inteligencia, aprenden mejor estando en contacto con la naturaleza, relacionando conceptos y temas con aspectos de la naturaleza. Les gusta explorar, investigar y descubrir ambientes naturales y formas de vida naturales. Poseen una gran sensibilidad para reconocer, descubrir y convivir con las plantas, animales y otros elementos del medio natural. Son buenos para desarrollar actividades al aire libre, imitar sonidos onomatopéyicos, recordar nombres y características de los elementos del medio natural.

\section{Estrategias para estimular la inteligencia naturalista}

Walkman (citada por Gatgens, 2003) señala que la y el docente deben crear hábitat dentro de la clase, donde se cuiden plantas o animales. También es importante que las y los niños sean motivados a coleccionar objetos naturales, y que visiten museos de historia natural y centros naturales.

Mora y Vindas (2002) proponen un listado de materiales para favorecer esta inteligencia: lupas, material de ciencias, láminas, libros de cuentos, plantas, animales, documentales y mangueras.

\section{Inteligencia espiritual}

Antunes (2000) afirma que son personas con gran fervor religioso, con gran capacidad para entregarse al cuidado del prójimo, aun por encima de los intereses personales. Sin embargo, Gardner (1995) no la considera como una inteligencia completa, ya que no se ha encontrado en ninguna parte de la corteza cerebral que responda al funcionamiento de la inteligencia espiritual.

\section{EL JUEGO COMO ELEMENTO PARA ESTIMULAR LAS INTELIGENCIAS MÚLTIPLES}

El juego representa la máxima expresión de sentimientos, pues las y los niños comunican las sensaciones que éste les produce.

En la infancia, las acciones como ser, tener, hacer, coger, dar, amar, vivir o morir, no cobran sentido más que a través de los juegos. Por este motivo, se debe permitir el juego en todos los sentidos: con compañía, con agua, arena colorantes, texturas, con niños de edades dispares, con adultos y sin compañía. De esta forma, el niño y la niña experimentan y conocen los mundo que los rodea, mediante la construcción de sus propias teorías, las cuales se irán descartando o validando conforme se desenvuelve en el entorno.

La investigación de la que surge este artículo (Lizano y Umaña, 2005), tuvo como objetivo básico realizar una propuesta curricular basada en las inteligencias múltiples con niños y niñas de 5 y 6 años, la cual requirió de 31 sesiones de trabajo. 
La investigación recurrió al uso de instrumentos y técnicas validadas mediante criterio de jueces. Se usó la observación, la entrevista a padres y madres de familia, un cuestionario para docentes y una autoevaluación. Todos los instrumentos y técnicas buscaban ubicar el desarrollo de las diferentes inteligencias en los participantes y valorar su nivel antes y después de la experiencia.

La propuesta curricular que se puso en práctica se trabajó con diferentes actividades que permitían, en distintas sesiones, trabajar y estimular las capacidades o habilidades de las inteligencias. Esto se realizó mediante actividades lúdicas, el uso del portafolio y escucha de música, entre otros.

Se detallan a continuación algunos de los resultados más relevantes.

\section{Gráfico 1}

Las inteligencias múltiples desde la perspectiva de las madres y padres de familia

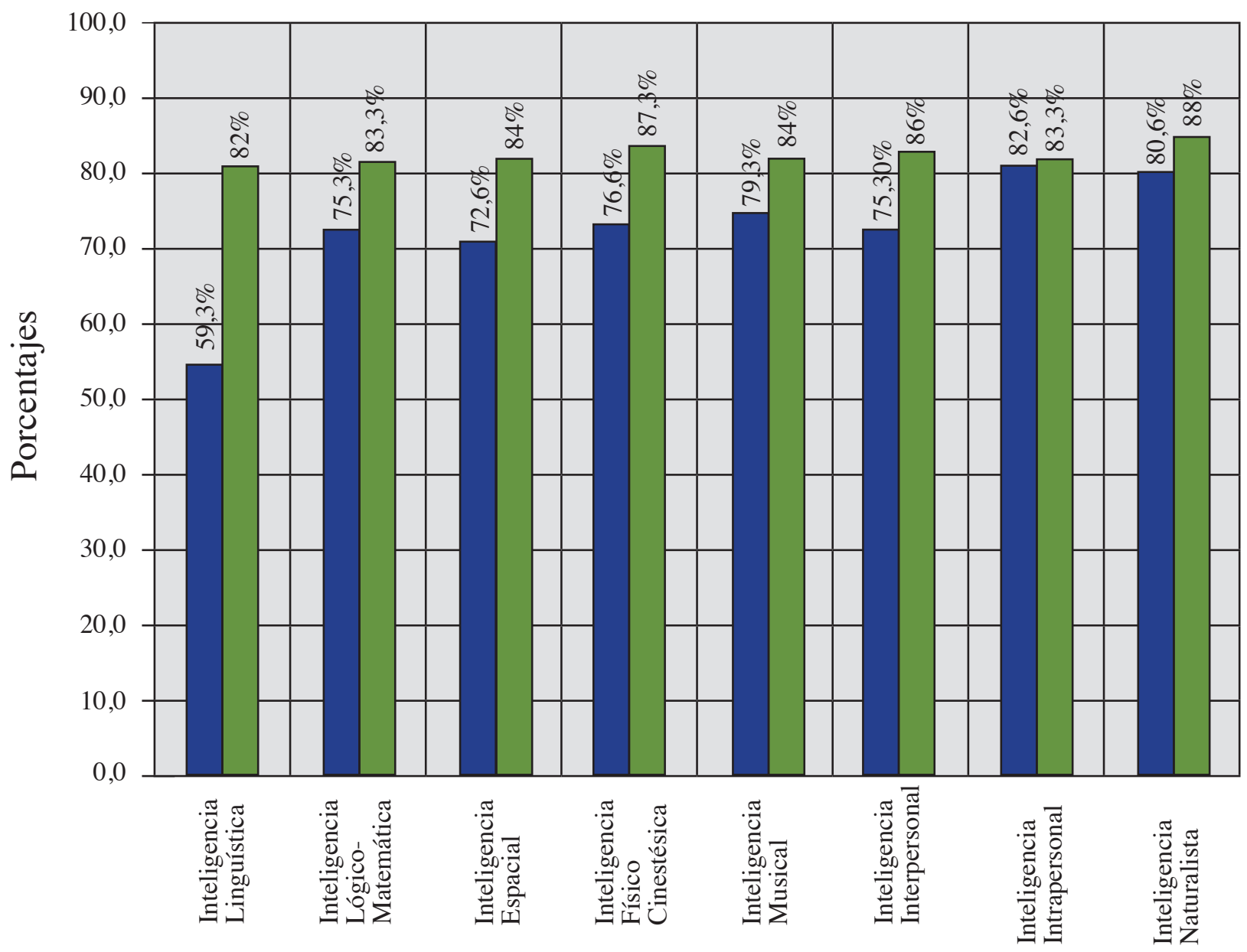

Tipos de Inteligencias

Pre-test

Post-test 
En la entrevista realizada a madres y padres de familia sobre las capacidad y habilidades de sus hijas e hijos en cada una de las inteligencias, realizada antes y después de la aplicación de la propuesta curricular, se nota como, de acuerdo con el criterio de madres y padres de familia, sus hijas e hijos han mostrado una evolución en las características y habilidades una vez finalizada la experiencia, lo cual se expresa en el contraste porcentual entre los resultados del pre-test y pos-test.

De igual manera, es notorio el progreso en la inteligencia lingüística, relacionada con las habilidades de escuchar cuentos, expresarse adecuadamente, el interés por la escritura y por narrar cuentos e historias imaginarias, entre otras.

\section{Gráfico 2}

Las Inteligencias Múltiples desde la perspectiva de las Investigadoras

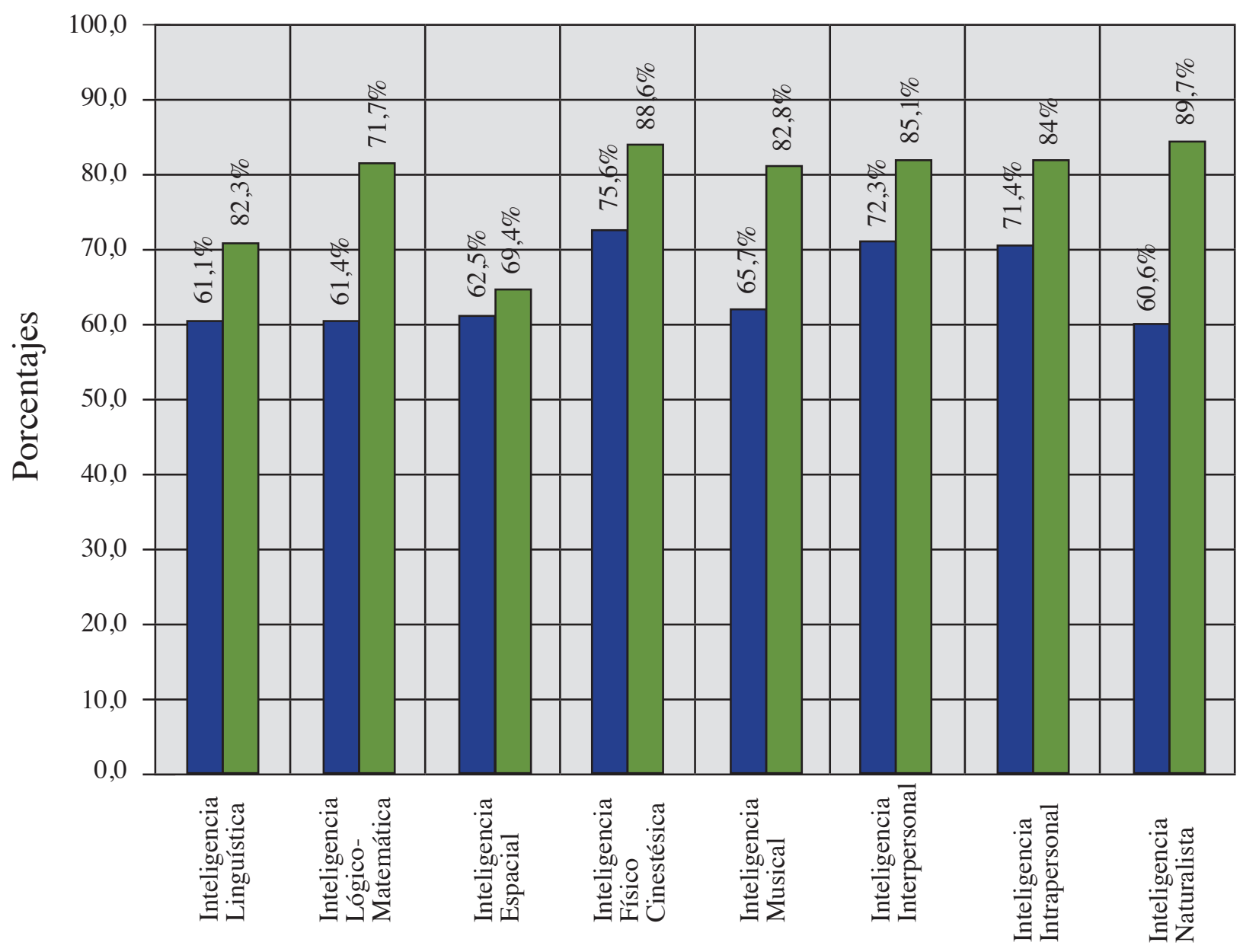

Tipos de Inteligencias

Pre-test

Post-test 
Al iniciar la aplicación de la propuesta mediante la observación, se identificaron las habilidades y características de los participantes para cada una de las inteligencias (pre-test), lo mismo que al finalizar la experiencia (pos- test).

Cabe señalar que se nota un avance más evidente (entre pre- test y pos- test) en las inteligencias naturalista, lingüística y musical. Este hecho permite pensar que la propuesta curricular aplicada podría haber fortalecido dichas inteligencias.

\section{AUTOEVALUACIÓN PARA NIÑAS Y NIÑOS}

Con respecto a la autoevaluación realizada a los pequeños, se presenta un cuadro que ejemplifica algunos de los aspectos evaluados por las niñas y los niños.

\section{Cuadro 1}

Opinión de niños y niñas acerca de los centros de inteligencia en que más les gustó trabajar

\begin{tabular}{|l|c|c|c|c|c|c|}
\hline \multicolumn{1}{|c|}{ Centro de inteligencia } & \multicolumn{2}{c|}{ Niños } & \multicolumn{2}{c|}{ Niñas } & \multicolumn{2}{c|}{ Total } \\
\hline & $\mathrm{F}$ & $\%$ & $\mathrm{~F}$ & $\%$ & $\mathrm{~F}$ & $\%$ \\
\hline Lingüística & 2 & 16,7 & 1 & 7,7 & 3 & 12 \\
\hline Lógico-matemática & 3 & 25,0 & 5 & 38,5 & 8 & 32 \\
\hline Espacial & 2 & 16,7 & 2 & 15,4 & 4 & 16 \\
\hline Intrapersonal-interpersonal & 2 & 16,7 & 4 & 30,7 & 6 & 24 \\
\hline Cinestésica & 2 & 16,7 & - & - & 2 & 8 \\
\hline Musical & - & - & 1 & 7,7 & 1 & 4 \\
\hline Naturalista & 1 & 8,3 & - & - & 1 & 4 \\
\hline
\end{tabular}

$M=25$ Niños y niñas.

El cuadro permite observar que, en términos generales, las niñas y los niños mostraron gusto por los diferentes centro de inteligencia; no obstante, son el lógico- matemático, intra e interpersonal los que generaron mayor gusto por trabajarlos.

\section{VALORACIÓN DE LA PROPUESTA}

La docente a cargo del grupo destaca el hecho de que esta propuesta se convirtió en un proyecto novedoso, pues está dirigido a que los menores sean quienes construyan por sí mismos el aprendizaje, por medio de distintas pautas que se les va dando, como los diversos materiales, los cuestionamientos acerca de las diversas temáticas por trabajar, entre otros lineamientos.

Se consideró positivo el hecho de que la propuesta estuviera basada en actividades lúdicas, dinámicas y diferentes a las que los menores estaban acostumbrados; esto los motivó a participar e integrarse al proyecto en forma activa. 
En cuanto a los aspectos por mejorar, la propuesta podría incluir la responsabilidad de los participantes, sobre todo, con respecto a la padres y madres de familia, quienes no lograron integrarse enteramente, debido al poco conocimiento y preparación de muchos de ellos.

Con respecto a los cambios en el aprendizaje de las niñas y los niños, la propuesta generó cambios en todos los aspectos, por lo que hubo un beneficio en la conducta y el comportamiento.

Se considera que la aplicación de la propuesta curricular puede convertirse en una buena opción para que las y los docentes de educación preescolar, la ejecuten en las aulas, pues provoca un impacto positivo en todas las capacidades de los menores.

\section{CONSIDERACIONES FINALES}

A raíz de la aplicación de la propuesta curricular sobre inteligencias múltiples, han sido innumerables los aprendizajes construidos a lo largo de las treinta y dos sesiones de trabajo con el grupo de niños y niñas.

Mediante la aplicación de la propuesta curricular y de las opiniones de madres y padres de familia, fue posible identificar en las y los niños preescolares las características y habilidades de las diferentes inteligencias.

Al finalizar la aplicación, se destaca que el centro de inteligencia preferido tanto por los niños como por las niñas, fue el lógico-matemático, esto posiblemente se deba a que los menores participantes encontraron en el centro de estudio una serie de materiales llamativos.

Al analizar los aspectos en los cuales los niños manifestaron mayor dificultad, resalta que la actividad más difícil de llevar a cabo, fue el hecho de hacer amigos (inteligencia interpersonal). Por el contrario, las niñas, en su mayoría presentaron más dificultades en la ejecución de labores motoras finas (inteligencia cinestésica).

En cuanto a las experiencias de los diferentes tipos de inteligencias, puede concluirse, que existe mayor preferencia por parte de los varones hacia las inteligencias lingüística, intrapersonal y musical. Las preferencias de las niñas se inclinan hacia las habilidades lingüística, lógico- matemática, musical y naturalista.

El trabajo con la propuesta curricular sobre inteligencias múltiples constituyó una novedosa manera de trabajar con preescolares, al utilizar una amplia variedad de juegos específicos para cada inteligencia, enfocadas en el trabajo con niñas y niños. De la misma manera, se destacan los cambios presentados por los participantes en cuanto al mejoramiento en las habilidades motoras finas y gruesas, el aumento en la creatividad y la curiosidad.

Por ultimo, es importante considerar que una práctica pedagógica basada en la Teoría de las inteligencias múltiples, implica conocer, estimular, propiciar las diferentes habilidades para cada inteligencia, así como fomentar y favorecer el desarrollo de aquellas áreas en las que niños y niñas presentan habilidades, lo cual es aplicable cuando se desea realizar un proceso de aprendizaje, independientemente de la metodología utilizada. Por eso, la función docente es esencial.

Para trabajar con inteligencias múltiples, es apropiado contar con los materiales necesarios para estimular las ocho inteligencias.

El trabajo con las madres y padres de familia en un taller, es esencial para motivarlos y darles un panorama más amplio de lo que se pretende realizar con sus hijas e hijos. 


\section{REFERENCIAS}

Antunes, C. (2000). Estimular las Inteligencias Múltiples. ¿Qué son, cómo se manifiestan, cómo funcionan? Madrid, España: Narcea S. A.

Armstrong, T. (2001). Inteligencias Múltiples: cómo descubrirlas y estimularlas en sus hijos. San José, Costa Rica: Grupo Editorial Norma.

Campbell, L., Campbell, B.,y Dickenson, D. (2002). Inteligencias múltiples. Usos prácticos para la enseñanza y el aprendizaje. Buenos Aires, Argentina: Editorial Troquel S. A.

Doltó, F. (2000). Las etapas de la infancia: nacimiento, alimentación, juego, escuela (1ª ed.). Barcelona, España: Editorial Paidós.

Gardner, H. (2001). El maestro de la inteligencia no artificial: la definición de Howard Gardner de listo todavía causa controversia. Ponencia presentada en el Congreso EDUCA 2001, San José, Costa Rica.

Gardner, H. (2001). Una multiplicidad de inteligencias. Ponencia presentada en el Congreso EDUCA 2001, San José, Costa Rica.

Gardner, H. (2001). La inteligencia reformulada. Las inteligencias múltiples en el siglo XXI. Barcelona, España: Ediciones Paidós.

Gardner, H., Feldman, D., y Krechevsky, M. (2000). El Proyecto Spectrum (1): Construir sobre las capacidades infantiles. Madrid: Edición Morata.

Gardner, H. (1995). Inteligencias Múltiples. La teoría en la práctica. Barcelona: Paidós.

Gardner, H. (1994). Estructuras de la mente. La teoría de las Inteligencias Múltiples. México, D. F.: Fondo de Cultura Económica.

Gardner, H. (1987). Arte, mente y cerebro. Una aproximación cognitiva a la realidad. Barcelona: Paidós.

Gardner, H. (1983). Frames of mind: The theory of Multiple Intelligences. New York: Basic Books.

Gatgens, G. (2003). Inteligencias Múltiples: Enseñar a los niños en la forma en que ellos aprenden. Tesis de maestría no publicada, Universidad Nacional, Heredia, Costa Rica.

Lapalma, F. (s.f.). La Teoría de las Inteligencias Múltiples y la Educación. Recuperado el 16 de noviembre de 2006 de www.lapalmacosultin.com 
Lizano, K. y Umaña, M. (2005). Aplicación de una propuesta curricular basada en la teoría de las Inteligencias múltiples con niños de 5 y 6 años en un Jardín Infantil Público. Tesis de licenciatura no publicada, Universidad Nacional, Heredia, Costa Rica.

Mora y Vindas. (2002). Sistematización del diseño de una propuesta curricular basada en la teoría de las inteligencias múltiples para niños de 5 y 6 años. Tesis de licenciatura no publicada, Universidad Nacional, Heredia, Costa Rica.

Valverde, H. (2003). Aprendo haciendo. Material didáctico para la educación Preescolar. San José, Costa Rica: Editorial de la Universidad de Costa Rica.

Zamora, D. (1999). La apreciación musical en el Jardín Infantil. Preescolar, 16, 10-13. 